\title{
PRODUÇÃO DE SUBJETIVIDADES NO TRABALHO EM UMA UNIDADE DE TERAPIA INTENSIVA PEDIÁTRICA
} LA PRODUCCIÓN DE SUBJETIVIDADES EN EL TRABAJO EN UNA UNIDAD DE CUIDADOS INTENSIVOS PEDIATTRICA PRODUCTION OF SUBJECTIVITIES AT WORK IN A PEDIATRIC INTENSIVE CARE UNIT

http://dx.doi.org/10.1590/1807-0310/2017v29161193

Tereza Cristina Peixoto, Izabel Christina Friche Passos e Maria José Menezes Brito Universidade Federal de Minas Gerais, Belo Horizonte/MG, Brasil Jorge Manuel Nunes Ramos do Ó Instituto de Educação da Universidade de Lisboa, Lisboa, Portugal

\section{RESUMO}

Objetivou-se analisar a micropolítica das relações interprofissionais em uma unidade de terapia intensiva pediátrica. Trata-se de um estudo com abordagem qualitativa, de cunho cartográfico, com observações da dinâmica das relações entre os sujeitos, entrevistas com 14 profissionais, no período de junho a agosto de 2014. As relações interprofissionais são constituídas em um território híbrido formado pela interseção dos saberes biomédicos, práticas de trabalho intervencionistas com aparelhos tecnológicos, reguladas por normas, protocolos e pelo lidar com crianças e seus pais. $\mathrm{O}$ afeto despertado nos profissionais frente à espontaneidade e sofrimento de crianças desestabiliza o plano normativo e científico do trabalho em prol da estabilização orgânica das crianças, desencadeando novos agenciamentos dos profissionais, ora flexibilizando as normas, ora intensificando comportamentos controladores e perfeccionistas. Aponta-se a importância da potencialização dos agenciamentos inventivos dos profissionais e criação de dispositivos para ações coletivas e saberes que promovam a associação da clínica da vida junto à da sobrevida.

Palavras-chave: UTI pediátrica; relações interprofissionais de saúde; cuidado em saúde.

\section{RESUMEN}

Este estudio tuve como objetivo analizar las relaciones interprofesionales y micropoliticas en una unidad de cuidados intensivos pediátricos. Se trata de un estudio con un enfoque cualitativo, de carácter cartográfico, con observación de la dinámica de las relaciones entre los profesionales y entrevistas con 14 profesionales llevadas a cabo de junio a agosto de 2014. Las relaciones interprofesionales se constituyen en un territorio híbrido formado por la intersección del conocimiento biomédico, prácticas intervencionistas con dispositivos tecnológicos, regulados por normas, protocolos y por el tratamiento a los niños y sus padres. El afecto despertado en los profesionales frente a la espontaneidad y el sufrimiento de los niños desestabiliza el plan normativo y científico de lo trabajo em favor de la estabilización orgánica de los niños, desencadenando nuevos agenciamientos de los profesionales, ora flexibilizando las normas, ora intensificando comportamientos controladores y perfeccionistas. Se señala la importancia de la potenciación de los agenciamientos inventivos de los profesionales y creación de dispositivos para acciones colectivas y saberes que promuevan la asociación de la clínica de la vida a de la supervivencia.

Palabras clave: UCI pediátrica; relaciones interprofesionales de salud; cuidado de la salud.

\begin{abstract}
This study aimed to analyze the micropolitics of interbranch relations in a pediatric intensive care unit. It is a study with a qualitative approach, of cartographic character. Observations of the dynamics of relationships between the professionals and interviews with fourteen professionals from June to August 2014 were carried out. Interbranch relations are constituted in a hybrid territory formed by the intersection of biomedical knowledge, interventionist work practices with technological gadgets, wich are regulated by standards, protocols, and by dealing with children and their parents. The affection aroused in professional front of spontaneity and children's suffering destabilizes the regulatory and scientific plan of work towards the organic stabilization of children, unleashing new agencies of the professionals, sometimes loosening the rules, sometimes intensifying behaviors controllers and perfectionists. This paper also points out the importance of empowering the professional's inventive agencies, and creating mechanisms for collective action and knowledge towards promoting the clinical association of life with the survival.
\end{abstract}

Keywords: pediatric ICU; interbranch relations of health; health care. 


\section{Introdução}

A unidade de tratamento intensivo pediátrica (UTIP) atende crianças em estado crítico de adoecimento que necessitam de procedimentos invasivos, na faixa etária de 29 dias a 14 ou 18 anos, sendo esse limite definido pelas rotinas de cada instituição. Trata-se de uma unidade com características complexas que abrangem profissionais especializados, aparelhos sofisticados, práticas intervencionistas, centralidade no saber médico com ênfase no orgânico e intensas demandas por acolhimento emocional das crianças e de seus pais (Ministério da Saúde, 2010).

A dinâmica do trabalho em saúde é de natureza coletiva e configura-se mediante a articulação de tecnologias duras, leve-duras e leves, sendo as primeiras relacionadas ao uso de equipamentos sofisticados e insumos, as segundas aos saberes estruturados das especialidades, aos protocolos e rotinas, e as terceiras aos relacionamentos com pacientes, familiares e equipe de trabalho (Merhy, 2002).

Nos hospitais públicos, principalmente nos universitários, coexistem exigências de qualificação profissional relacionadas a essas três tecnologias, tanto em função da aquisição de novos equipamentos sofisticados como pela contínua atualização de conhecimentos científicos na atenção à saúde e, também, com a necessidade da formação de uma nova cultura na atenção e gestão em prol da humanização, como preconizado pela Política Nacional de Humanização (PNH). Tal cultura objetiva o fortalecimento dos princípios do Sistema Único de Saúde (SUS), mediante a democratização das relações entre todos os sujeitos, profissionais, usuários e gestores e a integralidade da assistência (SUS) (Ministério da Saúde, 2009).

Um dos princípios fundamentais do SUS para qualidade e humanização assistencial é a integralidade. O conceito de integralidade pode ser entendido como uma imagem-objetivo que abrange diversas definições, como articulação entre os níveis de atenção em saúde, articulação entre os programas e políticas e atenção às dimensões do sujeito, quais sejam, orgânica, subjetiva, social, ética, política, estética e espiritual. Para tal, o modelo de atenção deve contar com organização em rede e com o trabalho em equipe (Mattos, 2004).

Na busca da construção do modelo de atenção e da gestão do SUS, novos modelos de gestão e de formação dos profissionais têm sido propostos. No entanto, apesar dos esforços, estudos apontam que os conflitos corporativos entre os profissionais, em especial nos hospitais, dificultam a gestão participativa e o trabalho em equipe com vistas à integralidade (Bernardes, Cecilio, Évora, Gabriel, \& Carvalho, 2011).

No entanto, nesses modos de organização hierarquizada e fragmentária existe uma zona de indiscernibilidade acontecimental, permeada por um conjunto multilinear de fluxos de força, que não descobre apenas sujeitos e objetos, mas antes regimes de desequilíbrio permanente frente aos encontros entre os diferentes sujeitos, profissionais, pacientes e familiares em situações inusitadas. Esses desequilíbrios são característicos do trabalho em saúde e potencializam a invenção de novos arranjos. Derivação e mutação são as suas características dominantes.

Dentre os setores do hospital, na Unidade de Terapia Intensiva, por exemplo, estamos em face de formação social que se compõe de intensas relações de força, considerando que o lidar com crianças e com seus pais desperta o envolvimento dos profissionais (Bettinelli \& Erdmann, 2009) e pode provocar desestabilizações afetivas.

A partir do exposto, o objetivo deste estudo foi analisar a micropolítica das relações entre os profissionais de saúde em uma unidade de terapia intensiva pediátrica. Estudos desta natureza podem contribuir para a construção de novas estratégias para a integração da equipe, bem como para a potencialização de agenciamentos em prol da ampliação dos modos de viver e de se relacionar dos sujeitos.

Este estudo se alinha às pesquisas desenvolvidas nas últimas décadas em prol da produção de subjetividades para o fortalecimento da cultura do SUS, como apresentado por Ferreira et al. (2011). Dentre essas, as que mais se relacionam ao presente estudo abordam a inseparabilidade entre as práticas de atenção e de gestão em saúde proposta por Campos (2000), Ayres (2001), dentre outros, como também as discussões em torno da autonomia dos indivíduos e coletivos para a promoção da saúde, como as de Carvalho e Gastaldo (2008), Perrela e Ferreira (2012), dentre outros. Nossa contribuição é considerar o setor de tratamento intensivo pediátrico como um local também privilegiado para o cuidado integral, apesar de predominantemente destinado a intervenções orgânicas. Ademais, entendemos que a micropolítica é a política do minoritário, da resistência aos instituídos, em que residem as disputas por outros modos de ser-existir-agir, sendo força instituinte promotora de transformações (Ceccim \& Merhy, 2009). 


\section{Percurso metodológico}

Estudo com abordagem qualitativa, com interesse nos aspectos dinâmicos e subjetivos no trabalho em saúde (Minayo, 2010). O cenário foi a unidade de tratamento intensivo pediátrica de um hospital universitário, referência na assistência de um estado do Brasil. A referida unidade foi escolhida por sua complexidade, uma vez que envolve alta tecnologia, saberes estruturados das diversas especialidades profissionais e, ao mesmo tempo, demandas subjetivas.

Esta pesquisa se sustentou na cartografia, tal como proposta por Deleuze e Guattari, que busca romper com as dicotomias entre teoria e prática e representa um estudo-intervenção que convoca uma experimentação problematizadora na interação que se estabelece entre o pesquisador e seu campo de estudo (Deleuze \& Guattari, 1996). O acompanhamento dos processos de composição, decomposição e recomposição de territórios existenciais dos sujeitos produz novos agenciamentos nas relações entre pesquisados e pesquisadores, mediante reflexões críticas sobre suas vivências (Romagnolli, 2009). Trata-se, portanto, de uma pesquisa que busca a afirmação da realidade em sua potência de abertura de sentidos e invenção.

O cartógrafo mergulha no campo dos afetos, inventa pontes de linguagem, não apenas como fala, mas também como meios de expressão da produção desejante (Rolnik, 2006). Para tal, se interessa pelos afetos que vivencia nos encontros com os sujeitos e com os objetos do campo de estudo, o que ativa seu "olho vibrátil", conceito descrito por Rolnik (2006) como o olho que se afeta de modo intensivo pelo que vê, diferenciando do olho que vê as representações e a subjetividade a partir de uma superfície compacta e fixa.

Procuramos perseguir a análise mapeando a dinâmica relacional e subjetiva do coletivo em estudo, como as linhas de forças constitutivas do plano molecular, agenciamentos que resistem ao normatizado e constituem possibilidades de irrupção para novos modos de relação.

No percurso da pesquisa foram identificados devires na interação entre os sujeitos, máquinas, tecnologias, crianças e famílias. Os devires são entendidos como constituídos por processos singulares, intensivos, sendo de natureza impessoal e préindividual, configurando zonas de indiscernibilidade, que deflagram a multiplicidade de territórios existenciais (Deleuze \& Guattari, 1996).

Ante o compromisso cartográfico, em termos operacionais, foram utilizadas técnicas comuns a outras metodologias de pesquisa qualitativa, como observações e entrevistas com profissionais da UTIP no período de junho ao início de agosto de 2014. As observações e entrevistas foram feitas em diversos horários de trabalho e no plantão de um final de semana, em um total de 80 horas. Durante as observações, foram realizados apontamentos por tópicos sobre a organização do serviço, como os trabalhos eram realizados e as inter-relações entre os diversos sujeitos, com registros em diário de bordo. Foram registrados também os afetos e questionamentos despertados na pesquisadora, que produziram nova estética de existência na mesma.

As entrevistas, com roteiro semiestruturado, foram realizadas com 2 médicos, 1 enfermeira, 4 técnicas de enfermagem, 2 fisioterapeutas, 1 terapeuta ocupacional, 1 psicóloga, 1 nutricionista, 1 coordenador médico e 1 coordenador da enfermagem, perfazendo 14 profissionais. As perguntas norteadoras das entrevistas abordaram como é trabalhar em uma UTIP, como é lidar com crianças doentes, quais os fatores que facilitam e os que dificultam o trabalho, como são as relações interprofissionais, como é o trabalho em equipe, como são as reuniões e que efeito o trabalho na UTIP provoca na vida pessoal do profissional. No decorrer das entrevistas, outras perguntas surgiram na interação com os entrevistados.

$O$ início da pesquisa na referida unidade ocorreu logo que foi aprovada pelo Comitê de Ética e Pesquisa (CEP) da universidade e do Comitê de Ética do hospital. Os entrevistados foram esclarecidos sobre os objetivos da pesquisa, riscos, garantia do anonimato e o direito de interrompê-las. Em seguida, os participantes assinaram o Termo de Consentimento Livre e Esclarecido, conforme resolução do Conselho Nacional de Saúde n. ${ }^{\circ}$ 466/12. Os fragmentos dos relatos aqui apresentados estão identificados pela inicial da profissão do entrevistado para preservação do anonimato.

Os resultados e discussão serão apresentados concomitantemente, considerando-se os seguintes eixos analíticos: A engrenagem da UTIP; Micropolítica das relações: cena 1 - Instabilidade da criança, cena 2 - Morte de crianças e cena 3 - Criança que habita a UTIP; o Cuidado de si e dos outros na UTIP.

\section{A engrenagem da UTIP}

Para apresentar a afetação produzida na pesquisadora durante as observações, reportamo-nos à imagem do interior de uma engrenagem de uma máquina industrial. A UTIP é um setor fechado, cujas 
janelas de vidro não podem ser abertas, e, embora seja iluminada, a temperatura é constantemente fria. A organização espacial conta com quatro salas destinadas à assistência das crianças, incluindo duas salas para as crianças que necessitam de isolamento, perfazendo um total de dez leitos. Nas salas que possuem mais de um leito, eles se encontram dispostos em semicírculo. Esse tipo de organização permite a vigilância contínua das crianças e dos procedimentos técnicos de enfermagem, uma vez que o posto de enfermagem se localiza no centro da sala.

No ambiente, encontra-se presente o som contínuo de alarmes de aparelhos, quase sempre disparados, desencadeados por qualquer alteração nos parâmetros programados para medicações, alimentação, níveis de oxigênio, batimentos cardíacos, entre outros. Muitas crianças permanecem sedadas, inconscientes, ligadas a respiradores. A maioria é acompanhada por um de seus pais, em geral pela mãe. Na unidade estudada são atendidas crianças com doenças complexas e raras.

A UTIP em estudo é identificada pelos demais profissionais do hospital como tensa e propensa a conflitos. Essa informação ocasionou preocupação na pesquisadora e retraimento no início da pesquisa, pelo receio de recusa da participação dos profissionais. Contudo, a receptividade foi surpreendente, sendo demonstrado interesse dos profissionais com o tema.

Na UTIP, o trabalho é rotineiro, e os processos distintos entre as categorias profissionais. Os médicos possuem autonomia nas decisões quando comparados aos demais. A unidade é altamente regulamentada por normas, rotinas, protocolos e leis, regulamentação que visa a assegurar os direitos dos pais, crianças e dos profissionais.

Esse conjunto de regulações está distribuído nas paredes do setor, como na porta de acesso à UTIP, na sala de prontuários, nos postos de enfermagem e disposto nas bancadas do setor e na intranet. Essa visibilidade contínua de normas parece intensificar uma estrutura de vigilância e de controle no cotidiano. Os saberes ou as verdades que fundamentam as rotinas e os protocolos assistenciais são provenientes da medicina tradicional com ênfase em intervenções orgânicas, sustentados por evidências científicas.

Podemos dizer que a UTIP representa o desenvolvimento da aliança da tecnologia com a medicina, no que se refere às intervenções sobre o organismo dos sujeitos em prol do prolongamento da vida orgânica, da sobrevivência. Os Centros de Tratamento Intensivo surgiram como um dos setores mais sofisticados dos hospitais, contando com um arsenal tecnológico para atendimento em alta complexidade a pacientes com instabilidade orgânica, que necessitavam de intervenções e de monitoramento contínuo, abrangendo várias patologias e faixas etárias. Posteriormente, foram criadas as Unidades de Tratamento Intensivo específicas por patologia, como a Unidade Coronariana, ou por faixa etária, como a Unidade de Tratamento Intensivo Pediátrica e Neonatal. Esses setores são monitorados e regulamentados pela Agência Nacional de Vigilância Sanitária (ANVISA) (Resolução no 07/ 2010).

Salienta-se que a partir do século XVIII foram criadas novas formas de governo, com utilização de estratégias sutis de governo, subsidiadas pelos conhecimentos biológicos, da medicina, da epidemiologia, da estatística e da economia para regular a vida da população e ao mesmo tempo estimular o desenvolvimento do liberalismo econômico. Essas estratégias, nomeadas como governamentalidade, configuram novos dispositivos aliados aos antigos mecanismos disciplinares que produzem modos de pensar e de se relacionar dos indivíduos. Tais estratégias são sutis. Por meio delas, o Estado assegura os direitos sociais, como a garantia de saúde e longevidade da população, e regula os comportamentos da população (Foucault, 2008).

A noção de governamentalidade centraliza as relações éticas dos sujeitos com mecanismos de poder que se ampliam e se dirigem a homens livres, que se percebem como indivíduos autônomos. As ideias de dominação são substituídas por ideias que remetam a tecnologias de regulação e de autorregulação (Foucault, 2008; Ó, 2003). Mesmo em um plano micropolítico e no quadro de uma organização específica, a perspectiva metodológica que adotamos permite descobrir conexões, pontos de contato, continuidades múltiplas entre, por um lado, diferentes formas de governo - associando estruturalmente o nível das relações interpessoais e das instituições dispersas no interior da sociedade com o governo político, entendido esse como o exercício do Estado soberano - e, por outro, as tecnologias do eu, ou seja, os modos como todos os indivíduos veem, se cuidam e se conduzem a si próprios. Em uma palavra, a arte de governo de todos e de cada um é a mesma.

Compreende-se, pois, a UTIP como local privilegiado para a análise da produção de subjetividade por meio do entrelaçamento de mecanismos disciplinares hierarquizantes, normatizadores, e de mecanismos sutis de tecnologias de poder, que podem ser identificados nos modos de pensar dos profissionais e de se relacionar com predomínio dos saberes biomédicos. 
A dinâmica rotineira do trabalho dos profissionais frequentemente é invadida por movimentos, desencadeados por acontecimentos, que instabilizam esse cenário, apontando para novos fluxos de forças e afetos. Um desses acontecimentos se dá nos dias em que o grupo de palhaços, composto por estudantes de medicina, visita o setor, o que ocorre uma vez por semana. Eles brincam com as crianças, com seus pais e com os profissionais. Os palhaços contribuem para novas formas de expressão de sentimentos, trazendo alegria.

\section{Micropolítica das relações}

Foram identificados acontecimentos exemplares que apontam para movimentos nos relacionamentos entre os sujeitos, desterritorialização e desestabilizações afetivas na unidade. Entende-se como acontecimento um fenômeno que provoca ruptura na organização do cotidiano, fazendo emergir novos arranjos e potencializando novos modos de relacionamentos entre os sujeitos (Ó, 2003). Os acontecimentos serão descritos por cenas que possibilitam análises da micropolítica das relações, intituladas como: A Instabilidade orgânica de crianças, Morte de crianças e Situação de criança que habita a UTIP.

\section{Cena 1 - Instabilidade da criança}

No momento de instabilidade orgânica de uma criança, gradativamente se configura ao seu redor uma nova formação, um devir, que podemos nomear como profissionais-criança-aparelhos em que os profissionais parecem se integrar aos aparelhos ligados aos corpos das crianças, principalmente as técnicas de enfermagem, que atuam continuamente. São momentos em que assistimos a uma engrenagem harmônica e altamente articulada em funcionamento, como se fosse somente um corpo profissionaiscrianças-aparelhos. Os profissionais se comportam de modo mais silencioso, mas ativos, solidários e atuam de modo integrado entre si. São momentos de forte afetação, em que se confundem máquinas/aparelhos e sujeitos. Os profissionais se dedicam intensamente a sua atividade, e muitas vezes se esquecem até mesmo de ir ao banheiro, de se alimentar, e frequentemente ultrapassam o horário de saída do plantão.

O cenário que se organiza perante a instabilidade orgânica da criança permite evidenciar a integração entre os profissionais em situações de crise. Situações de vulnerabilidade e de incerteza são apontadas como desencadeadoras de comportamentos solidários e práticas integradas por parte dos profissionais (Backes, 2012).
Retomando a análise sobre o devir profissionaiscrianças-aparelhos, os aparelhos parecem ganhar vida à medida que são ligados aos corpos infantis, substituindo funções de alguns órgãos, como os respiradores, aparelhos de hemodiálise, sondas nasoentéricas, entre outros. Ressalta-se também a interação contínua estabelecida entre os profissionais e os aparelhos, como se houvesse comunicação entre eles ou como se os aparelhos fossem extensão de seus corpos para realização do trabalho.

Entende-se que a relação com aparelhos tecnológicos é também produtora de subjetividades. A subjetividade é heterogênea, formada por componentes semiológicos significantes, que se manifestam por meio da família, da educação por componentes fabricados pela indústria da mídia, do cinema, e pelas dimensões semiológicas a-significantes, como máquinas informacionais de signos, que veiculam significações que escapam às axiomáticas linguísticas. A parte não humana, pré-pessoal da subjetividade, corresponde às instâncias identificatórias com interações institucionais de diferentes naturezas, tais como os computadores e os universos de referência incorporais, como a música e as artes plásticas (Guattari, 1992).

\section{Cena 2 - Morte de crianças}

Diante de situações de terminalidade de crianças na UTIP, desencadeia-se um novo devir expresso na unidade profissionais-crianças-pais, em uma afetação intensiva com as crianças e, ao mesmo tempo, com seus pais.

Diante desse acontecimento, médicos e outros profissionais brincavam ou acariciavam as crianças, se mantendo em diversos momentos próximos delas, como aponta o relato de um médico entrevistado, que se referiu a esse acontecimento como envolvimento dos profissionais: o que me preocupa é a questão emocional às vezes dos profissionais, como eles ficam envolvidos (Méd. 1).

Diante dessa afetação com crianças e seus pais, alguns médicos manifestavam novos arranjos relacionais na UTIP, assim como mães, pais ou as próprias crianças frente aos demais profissionais. Como exemplo, um desses médicos retornou ao plantão de madrugada para acompanhar uma criança enferma. Outro médico discutiu com uma técnica de enfermagem pela escolha de um filme com muitas cenas de sangue para a criança assistir. Segundo profissionais da enfermagem, esses médicos às vezes sugeriam que as mães monitorassem o trabalho das técnicas de enfermagem, o que gerava muitas tensões 
entre profissionais e pais: Os pais ficam morrendo de medo. Ficam perguntando o que a gente tá fazendo o tempo inteiro, falam assim: Ah! Fulano de tal falou para eu vigiar vocês (Enf. 1).

Essa intensificação dos afetos entre profissionaiscriança-pais em alguns momentos produz os conflitos entre a equipe e gera sofrimento no trabalho, principalmente em decorrência da dificuldade dos profissionais em lidar com situações incontroláveis, como mortes inesperadas. Em face de fluxos de afetos que em seus movimentos se desorganizavam ou requeriam novas composições, eram evidentes as relações de tensão e conflitos entre os profissionais.

Consideramos a concepção da realidade constituída de modo multilinear no entrelaçamento de territórios molar e molecular: o primeiro constituído pelo predomínio de normas, leis, classificações, hierarquizações, em um plano de identidades fixas, saberes estruturados e objetivantes; o segundo, o molecular, constituído pelos relacionamentos entre os indivíduos, em um plano de consistência, de incertezas, de instabilidades e de agenciamentos com linhas flexíveis. Em um movimento contínuo da vida, os sujeitos circulam repetidamente nesses territórios e planos em busca da construção de novas formas de viver e de se relacionar (Deleuze \& Guattari, 1996).

Nesse entendimento, as vivências caóticas e instáveis são potentes para a transformação dos relacionamentos e singularização dos agenciamentos coletivos. A singularização é descrita como um modo de reapropriação do indivíduo dos componentes da subjetividade, em uma relação de expressão e criação, que resiste à submissão da subjetividade à ordem dominante. Esse processo é sempre coletivo, uma vez que a produção do desejo, da sensibilidade, da fala é adjacente a uma multiplicidade de agenciamentos sociais, de produção de valor e de história (Deleuze \& Guattari, 1996).

No entanto, na UTIP, as instabilidades e caos são indesejáveis ante as práticas e os saberes hegemônicos em prol da estabilidade orgânica. Essa busca por estabilidade, quando tomada como modelo de funcionamento dos sujeitos, acirra mecanismos de controle e normalização da vida.

Entende-se que, nas vivências caóticas e de desconfiguração identitária, os sujeitos se angustiam e se instabilizam, podendo recorrer a antigas referências com vistas à criação de novos territórios. Entretanto, nesses momentos, alguns sujeitos na busca pela apreensão de novas referências recorrem a comportamentos ainda mais controladores (Deleuze \& Guattari, 1996). Nessa perspectiva analítica, compreende-se o sofrimento no trabalho e os comportamentos perfeccionistas adotados por profissionais em situações caóticas na UTIP.

Salienta-se que, a despeito dos conflitos, os profissionais da UTIP valorizam a norma e o rigor no controle do trabalho adotados por alguns membros da equipe: temos um rigor excessivo, o rigor não é ruim, mas em contrapartida ele traz um pouco de neurose (Enf. 1).

Ressalta-se que, na produção histórica da identidade profissional dos médicos, prevalece o imaginário social do perfeccionismo e da detenção da verdade (Scraiber, 1996). A identificação dos profissionais com esse imaginário social pode ser um dificultador para o lidar com os limites na atuação profissional e no trabalho em equipe. Segundo a Enf. 3: O pediatra gosta de cuidar de modo muito pormenorizado, nos detalhes. Eles são mais detalhistas, o que deu certo comigo (Enf. 3).

O imaginário social de perfeccionismo, na pediatria e no setor pesquisado, é ainda mais intenso em função da desnaturalização da morte de crianças a partir da modernidade e do compromisso histórico dessa especialidade com a longevidade das crianças (Pereira, 2006). Ademais, as intervenções clínicas e medicamentosas em crianças são mais suscetíveis a variações em função de seu peso e idade.

Durante o percurso cartográfico, os conflitos na relação entre as categorias profissionais e as queixas de adoecimentos entre os membros da equipe foram frequentes. Os profissionais procuravam a pesquisadora para expressar suas dificuldades, como se validassem suas impressões sobre os acontecimentos. Salienta-se que o grupo da enfermagem se encontrava fragilizado com insatisfações provenientes do tipo de vínculo de trabalho com a instituição. Havia diversos vínculos e contratos precários de trabalho, e os profissionais da enfermagem aguardavam a admissão de profissionais aprovados em um concurso, o que acarretaria um grande número de demissões.

Uma das estratégias de enfrentamento adotada pelos técnicos de enfermagem para lidar com as cobranças e com os conflitos foi a intensificação do controle sobre o próprio trabalho, como, por exemplo, com registros contínuos dos procedimentos e seguimento rígido de protocolos clínicos. Percebe-se que, nesse contexto, as normas representam segurança para os profissionais. Esses comportamentos apontam para a construção de saídas baseadas em atitudes normatizadas, que acentuam comportamentos controladores. 
A respeito do modo como os médicos lidam com a morte, entende-se que: "a identidade profissional do médico intensivista associa-se à missão de combater a morte. A briga da vida com a morte" (Menezes, 2000, p. 33). O desgaste vivido na batalha contra a morte pode ser recompensado quando uma vida é salva, de forma que o intensivista constrói uma autoimagem de heroísmo, muitas vezes associada à de excentricidade (Menezes, 2000). Essa dificuldade em lidar com a morte desperta sentimentos de fracasso, culpa e potencializa os conflitos entre os profissionais. O relato do Méd. 1 exemplifica o sofrimento dos médicos em lidar com a morte de crianças: é, muito envolvida, mas se envolve muito emocionalmente com alguns casos.

$\mathrm{O}$ acompanhamento de crianças em situação de terminalidade e o luto dos profissionais por sua perda são dificultados pela falta de espaço para a expressão de sentimentos e reflexões sobre a dimensão subjetiva e pela fragilidade do trabalho em equipe multiprofissional.

Perante dois acontecimentos de crianças falecendo, a cartógrafa se afetou pelo fato de os profissionais conversarem muito com os pais, mas não os escutarem, além de se afastarem deles nesses momentos. Os profissionais se reuniam entre si e muitas vezes choravam escondidos. Com inquietude perante a solidão das mães, a cartógrafa se aproximou para acompanhá-las, escutando choros e algumas poucas expressões verbais. Em geral, foram momentos para compartilhar a dor e o silêncio perante a morte. Tal ato provocou novos posicionamentos nos profissionais, pois, em outro momento, uma técnica de enfermagem ficou ao lado da mãe até a chegada do pai, e logo em seguida procurou a cartógrafa para abraçá-la.

Entende-se que o afeto ativa a potência e faz vacilar o eu identitário, representando possibilidades de ampliação nos modos de viver (Ceccim \& Palombini, 2009). Nesse entendimento, a ampliação da potência de vida subjetiva se dá pelas vivências de instabilidade, mas essa é uma lógica que difere da que predomina no setor, de estabilidade e controle para o prolongamento da vida orgânica.

\section{Cena 3 - Criança que habita a UTIP}

A internação prolongada de crianças na UTIP escapa à missão central da unidade, que é cuidar de quadros clínicos agudos, estabilizar as crianças e retorná-las para a enfermaria. No entanto, algumas crianças permanecem internadas por longo período em decorrência da necessidade de intervenção. Um desses casos apontou para a falta de reconhecimento da importância de ações promotoras de saúde, que exigem integração do trabalho dos diversos profissionais e participação ativa dos pais, mesmo na UTIP. No entanto, mesmo sem instituírem práticas de cuidado para tais situações, alguns profissionais se envolvem com as crianças e agenciam ações que transgridem normas frente às diversas situações inusitadas.

O acontecimento potencializou a afetação e instabilidades no setor ante o choro contínuo de uma das crianças. No setor, diversas crianças choram, principalmente os bebês, e nesses momentos os profissionais oferecem chupetas para minimizar o choro. Nesse acontecimento, contudo, a criança que estava chorando tinha longa permanência na UTIP, por um quadro grave de saúde e dependência de aparelhos. Encontrava-se no setor desde os 2 meses de vida, e estava com 8 meses, tinha poucas visitas, pois sua mãe morava distante.

Nesse dia, essa criança chorava continuamente, baixinho, com uma sonoridade que transparecia seu sofrimento e contagiava os profissionais e a pesquisadora. O setor estava silencioso, logo uma fisioterapeuta passou pelo leito e disse que aquele choro era vontade de colo, que era diferente de outros choros e que todos conheciam aquela criança. De fato, era um choro que parecia pedido de colo, de carinho.

Essa profissional olhou para a criança e a carregou dizendo: Não aguento ver isso! Assim que foi pegá-la, a criança se retraiu, e a profissional explicou que a criança estava acostumada desde pequena com toque das pessoas para injeções, acessos em seu corpo e intervenções por aparelhos, procedimentos muito dolorosos, por isso quando aproximava a mão para acariciá-la ou para carregá-la se comportava desse modo reativamente, como se fosse sentir dor com o toque. Mas, com delicadeza, tocou-a suavemente no rosto e carregou-a balançando. Logo a criança parou de chorar e adormeceu. A profissional disse: que se dane o protocolo que impede isso!

Os protocolos, geralmente por serem prescritivos, contemplam ações biomédicas, sem considerar a dimensão subjetiva e singular dos encontros entre os sujeitos, sendo esse um de seus limites (Schraiber, 1996). Esse ato da profissional exemplifica agenciamentos que transformam as relações para construção de novas formas de cuidado potencializadoras de acolhimento às crianças.

Para uma transformação da dimensão do cuidado, apostamos não só na importância da integração da equipe dos profissionais, mas também na capacidade de nos abrirmos para os acontecimentos, abandonando certezas e nos conectando a outros saberes e práticas, 
como na construção da transdisciplinaridade. O exercício de desterritorialização de um saber único, a que a realidade nos convoca, aponta para a consideração da dimensão política e coletiva em nosso trabalho (Sousa \& Romagnolli, 2012).

Nesse contexto, o lidar com a desterritorialização e as incertezas promove a produção de novos modos de relacionamentos dos profissionais consigo e com os demais, potencializando o trabalho integrado da equipe multiprofissional.

\section{Cuidado de si mesmo e dos outros}

Durante a pesquisa, a maioria dos profissionais do setor demandou intervenção para lidar com as dificuldades e dor despertados perante o sofrimento de mães e crianças. Segundo relataram, o serviço não dispõe de estratégias para cuidar dos profissionais e prepará-los coletivamente para lidar com a morte na UTIP. O relato da Téc. 1 exemplifica tal sofrimento: então é muito difícil, às vezes depois que você perde uma criança, você não ter com quem conversar, a gente sai daqui e tem uma vida lá fora esperando, e a gente tem que ir frustrado, dilacerado pra casa (Téc.1).

Mesmo os profissionais identificando suas dificuldades, não há estratégias para favorecer expressão de sentimentos e reflexões críticas para a formação da equipe na UTIP. O médico 1 relatou que o conjunto de médicos que trabalha na UTIP lida com a morte de crianças de modo diferente dos outros profissionais: a equipe tem um perfil muito parecido porque aguenta segurar isso. Mas assim... em cima de um tipo de cobrança e de estresse grande. Porque é assim, olha: se eu não for exigente o paciente morre (Méd.1). Mesmo afirmando que os médicos conseguem lidar com essa situação, o médico ressalta que esses profissionais se tornam mais exigentes e estressados.

Nota-se que o envolvimento dos profissionais se caracteriza por intensa dedicação ao trabalho e às crianças, algumas vezes extrapolando limites de vida pessoal e de respeito com os colegas de trabalho. Identifica-se que o modo como os profissionais cuidam de si mesmos se baseia em referenciais prescritivos ou biomédicos, de cuidados com o corpo, e nos ideais ascéticos modernos, com valorização da racionalidade, identidade fixa e busca por perfeição.

Entendemos que as sofisticadas técnicas de si empregadas nos novos dispositivos de governo apresentam um conjunto normativo de alteridentificações binárias aos sujeitos, como, por exemplo: negro/branco, mulher/homem/homossexual, professor/aluno, normal/anormal, que modelizam a relação dos sujeitos consigo e com os outros e dificultam processos de singularização e de reflexão crítica sobre si mesmos. A produção de novos modos de subjetividade é o resultado de interações que se operam tanto nos relacionamentos entre os sujeitos como no trabalho interno que realizam sobre si mesmos, possibilitando transformações que escapam de ideais ascéticos e transcendentes (Ó, 2003).

No território múltiplo da UTIP, outros profissionais apresentaram disposição a novas vivências, com modos diferentes de pensar a vida, como nos relatos: eu não faço questão de ser a melhor médica intensivista do serviço, eu faço meu serviço bem-feito para as crianças serem bem cuidadas, eu prefiro ter tempo para os meus filhos, dançar de noite e ter tempo para tudo (Méd. 3).

O relato dessa médica contrasta com o ideal de profissional difundido em um hospital universitário e na sociedade moderna altamente competitiva, quer dizer, o profissional que deve ser o melhor, e que é visto como aquele que detém conhecimento científico, com dedicação incondicional ao trabalho. Alguns médicos relataram que procuram não trabalhar somente na UTIP e assumem outros compromissos externos, que contribuem para um distanciamento das vivências do setor. Outros ainda relataram se apoiarem uns nos outros, saírem juntos e compartilharem dificuldades e sentimentos. Essas saídas foram relatadas como propiciadoras de enriquecimento subjetivo e representam agenciamentos potencializadores de transformações. Os profissionais de saúde, ao participarem da produção da vida dos usuários, podem construir um cuidar de si concomitante, não como viver de modo ideal, mas para viver de modo original (Ceccim \& Merhy, 2009).

\section{Conclusão}

A subjetividade produzida no contexto do trabalho da UTIP é sustentada por saberes científicos da medicina e em mecanismos disciplinares compostos por serialização das atividades, avaliação, normatização e controle. Ademais, há um intenso convívio com os aparelhos tecnológicos, necessários para a recuperação da saúde de crianças. A integração dos profissionais com os aparelhos e com os corpos das crianças faz emergir o devir profissional-aparelho perante a instabilidade orgânica de crianças.

No lidar com a espontaneidade de crianças, a afetação produzida nos profissionais faz com que vivenciem desterritorializações e incertezas, 
acontecimento que apontou o surgimento do devir profissional-criança-pais na UTIP. Nesse plano de consistência, observam-se diversos comportamentos em busca de saídas para lidar com tais situações: alguns transgridem normas para se dedicarem às crianças, outros se enrijecem a partir do horizonte normativo do setor e da ciência, intensificando condutas perfeccionistas e controladoras, produtoras de conflitos entre os profissionais. Estes últimos comportamentos geram sofrimento no trabalho. Outros profissionais refletem sobre a própria vida e os limites da prática e buscam atividades de prazer e encontros que ampliem as possibilidades de vida.

Foi possível constatar a intensa dedicação dos profissionais ao trabalho e às crianças e a necessidade do saber biomédico nas decisões e nas práticas da assistência à saúde nessa unidade. No entanto, apontase a importância da reflexão da equipe multiprofissional com relação à potência de projetos terapêuticos singulares para as crianças com longa permanência, a fim de ampliar a discussão e expressão de afetos e qualificar a assistência.

Ressalta-se que muitos profissionais relataram sentir muito prazer em trabalhar na UTIP, principalmente pelo fato de lidar com crianças, que demonstram gratidão e reconhecimento por pequenos atos de cuidado. Outro aspecto que provoca satisfação é o fato de acompanharem a recuperação de crianças em estado crítico, o que proporciona sentimento de realização profissional.

Salienta-se que a criação de si mesmo é um exercício ético-estético, é uma arte que tem na vivência do caos, do desconhecido, a possibilidade da construção de algo novo, de uma nova identidade, com ampliação das formas de se reconhecer e de se relacionar com os outros e consigo (Ceccim \& Palombini, 2009).

Evidencia-se que a UTIP é um território híbrido, potencializador de enriquecimento subjetivo para os profissionais, mas que necessita de espaço coletivo para reconhecimento dos afetos despertados, expressão de sentimentos e reflexões críticas sobre os acontecimentos inusitados a partir de novas referências para a produção de singularização. É importante uma reflexividade atenta às condições micropolíticas, que favoreça a coexistência de agonística entre o plano molar e molecular nos modos de viver dos sujeitos e coletivos. Na configuração das complexas relações e encontros, fortemente tensionados, há que se considerar que as respostas ao devir acontecimental podem não remeter para o regresso a um quadro normalizador das ações e dos sujeitos. No enfrentamento radical da existência humana, como no trabalho em uma UTIP, pode haver possibilidade de uma vida-outra.
Salientamos que este estudo se limita à unidade estudada, podendo potencializar novas pesquisas, como, por exemplo, análise sobre o lugar da arte como promotora de novas referências para a produção de subjetivação na UTIP.

\section{Agradecimentos}

Às agências de fomento: Coordenação de Aperfeiçoamento de Pessoal de Nível Superior (Capes), Fundação do Ministério da Educação (MEC) e ao Conselho Nacional de Desenvolvimento Científico e Tecnológico (CNPq). Processo n. : BEX10872/14-0.

\section{Referências}

Ayres, J. R. C. M. (2001). Sujeito, intersubjetividade e práticas de saúde. Ciênc. \& Saúde Coletiva, 6(1), 63-72. Acesso em 06 de setembro, 2015, em http://www.scielo.br/ scielo.php? script $=$ sci nlinks\&ref $=000133 \&$ pid $=$ S0102311X201100050000200014\&lng=en

Backes, J. C. (2012). Paradoxos do trabalho em equipe em um CTI-Pediátrico: entre procedimentos, sofrimento $e$ o cuidado. Dissertação de Mestrado, Programa de Pósgraduação em Saúde Pública, Escola Nacional de Saúde Pública Sérgio Arouca, Rio de Janeiro, RJ.

Bernardes A., Cecilio L. C. O., Évora Y. D. M., Gabriel C. S., \& Carvalho M. B. (2011). Modelo de gestão colegiada e descentralizada em hospital público: a ótica da equipe de enfermagem. Revista Latino-Americana de Enfermagem, 19(4), 1003-1010. Acesso em 02 de outubro, 2014, em http://www.scielo.br/pdf/rlae/v19n4/pt 20.pdf.

Bettinelli, L. A. \& Erdmann, A. L. (2009). Internação em unidade de terapia intensiva e a família: perspectivas de cuidado. Avances em Enfermeria, 27(1), 15-21. Acesso em 20 de junho, 2015, em http://www.bdigital.unal.edu. co/41787/1/12949-34820-1-PB.pdf

Campos, G. W. S. (2000). Um método para análise e co-gestão de coletivos. São Paulo: Hucitec.

Carvalho, S. R. \& Gastaldo, D. (2008). Promoção à saúde e empoderamento: uma reflexão a partir das perspectivas crítico-social e pós-estruturalista. Ciênc \& Saúde Coletiva, 13(Supl. 2), 2029-2040.

Ceccim, R. B. \& Merhy, E. E. (2009). Um agir micropolítico e pedagógico intenso: a humanização entre laços e perspectivas. Interface - Comunicação, Saúde, Educação,13(1), 531-542. Acesso em 08 de janeiro, 2013, em http://www.scielo.br/ pdf/icse/v13s1/a06v13s1.pdf

Ceccim, R. B. \& Palombini, A. L. (2009). Imagens da infância, devir-criança e uma formulação à educação do cuidado. Psicologia \& Sociedade, 21(3), 301-312. Acesso em 24 de janeiro, 2013, em http://www.scielo.br/pdf/psoc/v21n3/ a03v21n3.pdf

Deleuze, G. \& Guattari, F. (1996). Mil Platôs: capitalismo e esquizofrenia (Vol. 3). Rio de Janeiro: 34.

Ferreira, J. L. et al. (2011). Usos da noção de subjetividade no campo da saúde coletiva. Cadernos Saúde Pública, 27(5), 831-842. Acesso em 02 de outubro, 2015, em http://www. scielo.br/pdf/csp/v27n5/02.pdf

Foucault, M. (2008). Segurança, Território, População, Curso dado no Collège de France (1977-1978). São Paulo: Martins Fontes. 
Guattari, F. (1992). Caosmose: um novo paradigma estético. São Paulo: 34

Mattos, R. A. (2004). A integralidade na prática (ou sobre a prática da integralidade). Caderno de Saúde Pública, 20(5), 1411-1416. Acesso em 07 de fev., 2013, em http://www. scielo.br/pdf/csp/v20n5/37.

Menezes, R. A. (2000). Difíceis decisões: uma abordagem antropológica da Prática Médica em CTI. PHYSIS, 10(2), 27-49. Acesso em 02 de janeiro, 2012, em http://www. scielo.br/pdf/physis/v10n2/a02v10n2

Merhy, E. E. (2002). Saúde: a cartografia do trabalho vivo em ato. São Paulo: Hucitec.

Minayo, M. C. S. (2010). O desafio do conhecimento; pesquisa qualitativa em saúde (12a ed.). São Paulo: Hucitec.

Ministério da Saúde. (2009). HumanizaSUS: documento base para gestores e trabalhadores do SUS ( $4^{\mathrm{a}}$ ed.). Brasília, DF: Autor.

Ó, J. R. (2003). O governo de si mesmo; modernidade pedagógica e encenações disciplinares do aluno Liceal (último quartel do século $X I X$ - meados do século $X X$ ).

Lisboa: Educa.

Pereira, J. S. (2006). História da Pediatria no Brasil do século XIX a meados do século XX. Tese de Doutorado, Programa de Pós-graduação em História, Universidade Federal de Minas Gerais, Belo Horizonte, MG.

Perrela, A. C. \& Ferreira, J. L. (2012). Poder, saber e subjetivação: experiência de um grupo de saúde. Polis $e$ Psique, 2, 81-103.

Rolnik, S. (2006). Cartografia sentimental. Porto Alegre: UFRGS.

Romagnolli, R. C. (2009). A cartografia e a relação pesquisa e vida. Psicologia \& Sociedade; 21(2), 166-173.

Resolução n. 07, de 24 de fevereiro de 2010. (2010). Dispõe sobre os requisitos mínimos para funcionamento de Unidades de Terapia Intensiva e dá outras providências. Brasília, DF: Ministério da Saúde. Acesso em 20 de agosto, 2014, em http://www.anvisa.gov.br/hotsite/segurancadopaciente/ documentos/rdcs/RDC\%20N\%C2\%BA\%207-2010.pdf.

Schraiber, L. B. (1996). Ética e subjetividade no trabalho em saúde. Divulgação em Saúde para Debate, 12, 45-50. Acesso em 07 de junho, 2013, em http://www2.fm.usp.br/ $\mathrm{gdc} /$ docs/preventivapesquisa_4_cebes_divulgacao n 12 jul1996_pp45 50.pdf

Sousa, L. S. \& Romagnolli, R. C. (2012). Considerações acerca da articulação clínica, rizoma e transdisciplinaridade, Mnemosine, 8(1), 72-89.

Submissão em: 16/03/2016

$1^{\text {a }}$. Revisão em: 24/08/2016

$2^{a}$ Revisão em: 22/09/2016

Aceite em: 26/10/2016
Tereza Cristina Peixoto é psicóloga pela UFMG. Doutora em Saúde e Enfermagem, linha de pesquisa Planejamento e Organização dos serviços de saúde e de enfermagem pelo departamento de enfermagem da UFMG. Docente do Centro Universitário UNA em Belo Horizonte.

Endereço: Rua Bogotá, no 383, apto. 202. Bairro Jardim América. Belo Horizonte/MG, Brasil. CEP 30.421-392.

E-mail: terezacpc@hotmail.com

Izabel Christina Friche Passos é graduada em Psicologia; Mestre em Filosofia pela UFMG; Doutora em Psicologia Clínica pela PUC/SP; Pos-doutorado em Antropologia

Médica na Universitat Rovira i Virgili/Tarragona-Espanha.

Professora associada IV do Departamento de Psicologia e membro permanente do Programa de Pós-graduação em Psicologia da Fafich/UFMG. E-mail: izabelfrichepassos@gmail.com

Maria José Menezes Brito é graduada em Enfermagem pela PUC de Minas Gerais, Mestre em Enfermagem pela UFMG; Doutora em Administração pela UFMG; Pós-Doutorado na UFSC. Professora Associada II da Universidade Federal de Minas Gerais- Departamento de Enfermagem Aplicada. Credenciamento pleno doutorado no Programa de Pós-Graduação da Escola de Enfermagem/ UFMG.

E-mail:mj.brito@globo.com

Jorge Manuel Nunes Ramos do Ó é graduado em História e Mestre em História pela Universidade Nova de Lisboa;

Doutor em Ciências da Educação pela Universidade de Lisboa. Professor Associado do Instituto de Educação da Universidade de Lisboa, Portugal. E-mail: jorge.o@ie.ulisboa.pt 